DOI: $\underline{10.17805 / g g z .2020 .3 .5}$

\title{
Трактовки личности Петра Первого в современной науке и коллективной памяти россиян ${ }^{*}$
}

Т. П. Емельянова

Институт психологии РАН, г. Москва

Статья посвящена обзору интерпретаций значения личности Петра I для понимания исторического смысла его деяний. Приводятся данные исследования образов коллективной памяти различных групп россиян о Петре I. Для большинства наших современников Петр I остается наиболее значительной фигурой в истории России. Респонденты отмечают культурные преобразования, произведенные императором, укрепление армии и флота, строительство Санкт-Петербурга, «окно в Европу» и новый уровень развития России. Время его правления рассматривается как судьбоносное для дальнейтей истории России.

Показано, что влияние институциональной памяти (содержание школьных учебников истории, популярные художественные фильмы о Петре I), сфокусированной на заданные трактовки, порождает эффект превознесения императора и его деяний у широкой публики. Авторы практически единодушны в оченке величия его личности, восхваляют таланты императора, указывая на то, что он овладел различными науками и ремеслами и имел обширные знания в разных областях (законотворчество, военное искусство, дипломатия, история, география, столярное дело и т. д.).

Результаты научных исследований обнаруживают наличие глубоких противоречий в личности Петра I, а сама его личность представлена далеко не так однозначно. Объединяя имеющиеся оценки и суждения в этом направлении, можно указать на три группы мнений: «панегиристы», считающие, что Петр I является выдаюшейся личностью; «обличители», утверждающуие, что он разрушил сформировавшиеся русские традици и устои; «объективистыл, стремящиеся сбалансированно представить и заслуги, и недостатки деятельности Петра I. При этом, большинство авторов, несмотря на свою приверженность или негативизм по отношению к императору, указывают на ярко выраженную противоречивость его натуры.

\footnotetext{
* Исследование выполнено в рамках проекта РФФИ № 20-013-42001. The research was carried out within the framework of the project No. 20-013-42001 supported by the Russian Foundation for Basic Research.
} 
В итоге отмечается, что изучение научных интерпретаций деятельности Петра I в коллективной памяти россиян и в стереотипах, распространяемых средствами институциональной памяти, помогут лучше понять тенденции современного политического сознания.

Ключевые слова: Петр Великий; личность Петра I; внутренняя противоречивость личности; коллективная память; институцииональная историческая память

\section{Interpretations of the Personality of Peter the Great in Contemporary Science and the Collective Memory of the Russians}

T. P. Emelyanova

Institute of Psychology, Russian Academy of Sciences, Moscow

The article gives a review of interpretations of the significance of the personality of Peter I for understanding the historical meaning of his acts. It presents the data of a study on images of the collective memory about Peter I among various groups of the Russians. The majority of our contemporaries consider Peter I to be the most significant figure in the history of Russia. The respondents note the cultural transformations carried out by the emperor, the strengthening of the army and navy, the construction of St. Petersburg, the "window to Europe" and the new level of Russia's development. The time of his reign is regarded as crucial for the future fate of Russia.

It is shown that the influence of institutional memory (the content of school history textbooks, popular feature films about Peter I), focused on the given interpretations, generates the effect of the exaltation of the emperor and his deeds among the general public. The authors are practically unanimous in assessing the greatness of his personality, they praise the talents of the emperor, pointing out that he mastered various sciences and crafts and had extensive knowledge in different fields (lawmaking, military art, diplomacy, history, geography, carpentry, etc.).

The results of scientific research reveal the presence of deep contradictions in the personality of Peter I, and his personality itself is not presented so unambiguously. Combining the available assessments and judgments in this direction, we can point to three groups of opinions: "panegyrists" who believe that Peter I is an outstanding figure; "denunciators" who claim that he destroyed the established Russian traditions and principles; "objectivists" who strive to present both the merits and shortcomings of Peter I in a balanced way. At the same time, the majority of authors, despite their adherence or negativism towards the emperor, highlight the pronounced contradiction of his nature. 
As a result, it is noted that the study of scientific interpretations of the activities of Peter I in the collective memory of the Russians and in the stereotypes propagated by the means of institutional memory will help to better understand the trends of modern political consciousness.

Keywords: Peter the Great; personality of Peter I; internal contradiction of personality; collective memory; institutional historical memory

\section{ВВЕДЕНИЕ}

Более трех веков не ослабевает интерес специалистов разных областей знаний к личности и деяниям императора Петра Первого. Едва ли найдется социогуманитарная наука, представители которой не видели бы своего дисциплинарного ракурса в изучении деятельности императора. Историки, культурологи, политологи, искусствоведы, филологи открывают все новые аспекты петровской эпохи и ее последствий для российского государства. Между тем в многообразии подходов, предметных ракурсов изучения правления Петра I отчетливо просматривается отношение авторов к фигуре самого императора, его личности.

Цель нашей работы состоит в аналитическом обзоре интерпретаций значения личности Петра I в различных сферах общественного сознания современной России. Для прояснения авторской позиции требуется уточнить наше понимание содержания нескольких близких понятий: историческая наука, историческая память, коллективная память и массовая память. Все обозначающие их явления, хотя и имеют отношение к ментальному воспроизведению прошлого, тем не менее обладают своеобразием онтологии, содержания, механизмов функционирования и способов познания. Историческая наука как традиционная научная дисциплина призвана дать объективное знание о прошлом. Историческая память, напротив, идеологически ангажирована, она «продвигает» какую-либо интерпретацию событий прошлого, что неизбежно вызывает активный дискурс и полемику в обществе и столкновение разных трактовок. Коллективная память - это социально-психологический феномен, атрибут больших социальных групп (по М. Хальбваксу), своего рода обыденные интерпретации сведений, почерпнутых из самых различных источников: фильмов, научной и художественной литературы, школьных учебников, дискурса в СМИ и др. Взаимное воздействие этих форм исторического сознания общества разнонаправленно и не всегда предсказуемо. Петр I, являясь одной из наиболее значимых фигур отечественной истории, всегда становился предметом как научных исследований, так и идеологических трактовок. В то же время его личность неизменно присутствовала в обыденном историческом сознании людей, т. е. находилась в фокусе коллективной памяти. 
Огромный масштаб этой личности не подлежит сомнению. Преобразования, произведенные Петром I в государственной и общественной сферах России, по сей день будоражат умы. Достаточно сказать, что, как показывают проведенные нами эмпирические исследования (Емельянова, Кузнецова, 2013а; Емельянова, 2019), в коллективной памяти наших современников Петр I остается наиболее значительной фигурой в истории России.

\section{ОБРАЗ ПЕТРА I \\ В КОЛЛЕКТИВНОЙ ПАМЯТИ}

В анкетном исследовании социальных представлений о личности Петра I на выборке респондентов трех поколений (Емельянова, Кузнецова, 2013b) нами было показано, что большинство респондентов отмечают решительность императора, его целеустремленность и трудолюбие. Стиль правления Петра I частью респондентов рассматривается как либеральный, частью как авторитарный или деспотичный. Среди достижений Петра I респонденты предсказуемо отмечают, прежде всего, культурные преобразования, укрепление армии и флота, строительство Санкт-Петербурга, «окно в Европу» и новый уровень развития России.

Ядро социальных представлений о деяниях Петра I содержит ассоциации с реформами в армии, на флоте и связями России с Европой, ее ориентацией на западный путь развития (Емельянова, Кузнецова, 2013а). Респонденты разного возраста, различных политических взглядов чаще всего (с небольшими различиями) отмечают позитивный характер произошедших преобразований, подчеркивают необходимость реформ и уделяют особое внимание личности Петра І. Они позитивно оценивают развитие различных сфер жизни государства, придают особое значение деятельности Петра I в связи с обновлением России, ее связям с Европой. Время его правления выступает в памяти респондентов как судьбоносное, наделенное чертами «эпохальности», важное для дальнейшей судьбы России. Подобных взглядов придерживается большая часть респондентов. Лишь незначительная доля опрошенных составила особый тип «критиков» деятельности Петра.

Содержание представлений об эпохе Петра I различается в группах респондентов, принадлежащих к различным поколенческим когортам. Ядро социальных представлений об эпохе Петра I связывается с реформами в армии и флоте и связями России с Европой, ее ориентацией на западный путь развития. С возрастом расширяется контекст включения личности в исторический процесс: если в 20-25 лет респонденты рассматривают личность правителя как отдельную и главную предпосылку преобразования, то в 40-45 лет люди склонны к включению ее в общую систему государства, а в 60-65 лет - в систему мира и человеческого общества в целом. 


\section{ОБРАЗ ПЕТРА I \\ В ШКОЛЬНЫХ УЧЕБНИКАХ}

Анализируя полученное в эмпирическом исследовании содержание коллективной памяти, хочется назвать его хрестоматийным, если не стереотипизированным. Истоки этих образов памяти, по-видимому, нужно искать, прежде всего, в том, как организована историческая (институциональная) память, воплощенная, в частности, в содержании школьных учебников. Даже беглый обзор этих учебных текстов показывает, что авторы практически единодушны в оценке величия личности Петра Первого, в том, что он был примером служения Отечеству, вдохновлял окружавших его людей, считая, что если Бог дал ему власть, то именно он знает, что нужно народу и государству (Артемов, Лубченков, 2017). В учебниках восхваляются таланты императора, который слывет универсалом, человеком, сведущим в науках, управлении и ремеслах. Утверждается, что Петр легко находил общий язык с людьми разных социальных слоев и профессий (Сахаров, Баханов, 2013: 3637). Будучи государственным человеком, «Петр I умел определять наиболее важные задачи и находить пути их решения. <..> ...pасширил понятие возможного своей решительностью, цельностью натуры и твердой волей и заставил народ поверить в собственные силы» (Андреев и др., 2019: 54). Государь в своих преобразованиях полагал, что действует в интересах государства и на благо народа. Это царь-реформатор, который благодаря решительным преобразованиям изменил страну, вывел ее на европейский уровень (Кириллов, Бравина, 2016). Петр радикально менял устои прежней российской жизни, решительно заменяя их новыми образцами, почерпнутыми из практики других стран (Дворниченко, Кащенко, Флоринский, 2016). Как можно видеть из текстов школьных учебников истории, в характеристике Петра I преобладает портрет просвещенного монарха и великого преобразователя.

\section{ОБРАЗ ПЕТРА I \\ В ХУДОЖЕСТВЕННЫХ ФИЛЬМАХ}

Другим значимым источником «расхожих» образов коллективной памяти о Петре I служат популярные художественные фильмы. Среди них такие знаменитые киноленты, как «В начале славных дел» (1980), «Юность Петра» (1980), «Россия молодая» (1981-1982), «Петр Первый. Завещание» (2011) и др. Пафос этих фильмов, безусловно, «работает» на создание образа сурового, но справедливого, решительного правителя, гениального царяреформатора, созидателя новой России.

Вполне закономерно, что подобное давление институциональной памяти, сфокусированной на вполне однозначные смысловые линии и заданные 
трактовки, порождает эффект практически тотального превознесения императора и его деяний у широкой публики.

\section{ОБРАЗ ПЕТРА I \\ В НАУЧНЫХ ИССЛЕДОВАНИЯХ}

В трудах историков, культурологов и других специалистов личность Петра I занимает ведущее место в рамках тематики работ по петровской эпохе, но его фигура представлена далеко не так однозначно, как в институциональной трактовке. Среди полусотни научных статей последних пяти лет, работы, посвященные преимущественно анализу личности самого Петра I, заметно выделяются по количеству и составляют почти 25 \% всего объема текстов, опережая исследования о реформах государственного управления, армии и флота, законодательства, образования, культуры и эпохи в целом. Обращает на себя внимание тенденция авторов представить в современных трудах исторически сложившуюся палитру точек зрения на личность Петра I (см., например: Вализаде, 2011; Саркисьян, 2014; Джаббаров, 2019). Объединяя имеющиеся оценки и суждения, А. Г. Данилов выделяет три группы мнений:

- «панегиристы», считающие, что Петр I является выдающейся личностью, положившей начало новой эре развития российского государства;

- «обличители», утверждающие, что Петр I разрушил сформировавшиеся традиции и устои, что его реформы противоречили национальным и религиозным традициям России;

- «объективисты», стремящиеся сбалансированно представить и заслуги, и недостатки деятельности Петра I (Данилов, 2015: 158).

При этом большинство авторов, несмотря на свою приверженность или негативизм по отношению к императору, отмечают ярко выраженную противоречивость его натуры (Акунин, 2017; Анисимов, 2017; Бушков, 2018; и др.). Любознательность, фанатичное упорство в достижении цели оборачивались вспышками ярости и жестокости. Религиозность соседствовала с шутовством и святотатством. Масштабность замыслов сосуществовала с зацикленностью на мелочах и жаждой тотального контроля (Акунин, 2017: 26). Петр I воспринимался современниками как русский самодержец и одновременно как «чужой», «немец» (Анисимов, 2017), поскольку ассоциировался с иноземным образом жизни. Его бытовая грубость, непритязательность в одежде и даже неряшливость (Акунин, 2017) уживались с образованностью и высоким художественным вкусом.

Противоречивость и даже эклектика проявлялись и в его стратегии построения государства. С одной стороны, Петр I стремился создать современную европейскую державу, что и было основной целью его деятельности, a, с 
другой, пренебрегал теми важными тенденциями, которые отчетливо проявлялись в тот период в Европе: парламентаризм, система народного представительства, выборы. Западноевропейское просвещение было демократическим и городским, а Петр I шел по пути жесткого этатизма, основанного на тотальном подчинении. По мнению ряда авторов, им просто использовались инокультурные заимствования и достижения отдельных элементов западноевропейской системы хозяйства при укреплении самодержавной системы управления, а именно «имперская модернизация» (Палеолог, Чистова, 2014). При всей масштабности реформирования государства по «европейским лекалам» полномасштабной «модернизации менталитета» (Анисимов, 2017) не произошло. Преобразования общества аналитики называют своеобразной мимикрией, способом вхождения в другую культуру, без глубинного осмысления культурных процессов, затронувших Запад в Новое время. Между тем такое копирование, подражание у части высшего сословия вело к постепенному возрастанию интереса к иной культуре. Ряд представителей молодого поколения с пониманием относился к необходимости изучения наук. В целом политика Петра I привела к тому, что уже во времена его правления в среде дворянства наметилась тенденция к получению образования как необходимого условия для успешного прохождения последующей службы.

Однако реформы образования практически не затрагивали низшие сословия, тем самым, по мнению ряда авторов, реформы Петра Великого лишь ускорили раскол общественных слоев. Как отметил Ли Цзин, «в высших кругах общества развивалось просвещение, а нижние круги теряли свободу и становились рабами. Возник раскол в русской общественной культуре» (Ли Цзин, 2015: 115; см. также: Мезенцев С., Мезенцев И., 2018). Б. Акунин подчеркнул, что «для такого государства было нужно чрезвычайно дисциплинированное и в то же время не склонное к умничанью население. В идеальном мире Петра монарх - это Отец, а подданные - почтительные и послушные дети» (Акунин, 2017: 32). Писатель обозначил и еще одно внутреннее противоречие в мировоззрении Петра I: «Про Петра можно сказать, что он был россофилом, то есть патриотом страны России, но при этом отъявленным русофобом» (там же). Н. И. Костомаров писал: «Русский народ видел в своем царе противника благочестия и доброй нравственности; русский царь досадовал на свой народ, но настойчиво хотел заставить его силою идти по указанной им дороге» (Костомаров, 1995: 277) и подтверждал это словами самого императора: «С другими европейскими народами можно достигать цели человеколюбивыми способами, а с русскими не так: если б я не употреблял строгости, то бы уже давно не владел русским государством и никогда не сделал бы его таковым, каково оно теперь. Я имею дело не с людьми, а с животными, которых хочу переделать в людей» (там же: 278; см. также: Косто- 
маров, 1892). При этом, как считает Б. Акунин, «он был такого высокого мнения о своем положении, что с этой поднебесной высоты все подданные - хоть вельможа, хоть последний оборванец - казались ему холопами» (Акунин, 2017: 30). Тем не менее большинство современных аналитиков безусловно признают величие личности Петра I в части проведения ключевых реформ армии, флота, государственного строительства, образования и др.

\section{ЗАКЛЮЧЕНИЕ}

Имперские устремления Петра I задали вектор государственного строительства в России вплоть до 1917 г., и именно эта тенденция повлияла на дальнейшее социально-историческое развитие Советского Союза (Ли Цзин, 2015). Многообразие содержания исторического сознания относительно личности и деятельности Петра I отражает неоднозначность его политики. В то же время взаимовлияние разных форм исторического сознания российского общества может служить ориентиром для оценки позиций отдельных социальных групп. Тем самым изучение научных интерпретаций деятельности Петра I, образа его личности в коллективной памяти россиян, стереотипов, распространяемых средствами институциональной памяти, помогут лучше понять тенденции современного политического сознания.

\section{СПИСОК ЛИТЕРАТУРЫ}

Акунин, Б. (2017) Азиатская европеизация. История Российского государства. Царь Петр Алексеевич. М. : АСТ. 384 с.

Андреев, И. Л. и др. (2019) История России. Конец XVII - XVIII век. 8 класс : учебник / И. Л. Андреев, Л. М. Ляшенко, И. В. Амосова, И. А. Артасов, И. Н. Федоров. 5-е изд., перераб. М. : Дрофа. 218, [6] с.

Анисимов, Е. В. (2017) Петр Первый: благо или зло для России? М. : Новое литературное обозрение. 272 с.

Артемов, В. В., Лубченков, Ю. Н. (2017) История Отечества. С древнейших времен до наших дней : учебник для студ. учреждений сред. проф. образования. 21-е изд., стер. М. : Академия. 384 с.

Бушков, А. А. (2018) Петербург и петербуржцы или парадиз Петра I. М. : Капитал. 320 с.

Вализаде, Д. Р. (2011) Реформы Петра I как основа трансформации культурных ценностей в России [Электронный ресурс] // Современные научные исследования и инновации. № 5. URL: http://web.snauka.ru/issues/2011/ 09/2611 [архивировано в WaybackMachine] (дата обращения: 02.04.2020).

Данилов, А. Г. (2015) Россия на перекрестках истории XIV-XIX вв. СПб. : Алетейя. 436, [3] с. 
Дворниченко, А. Ю., Кащенко, С. Г., Флоринский, М. Ф. (2016) История России до 1917 года : учебник. М. : Юрайт. 453 с.

Джаббаров, Р. Р. (2019) Петр Великий в оценке Н. М. Карамзина // Вестник Волгоградского государственного университета. Серия 4: История. Регионоведение. Международные отношения. Т. 24. № 1. С. 98-108. DOI: 10.15688/jvolsu4.2019.1.8

Емельянова, Т. П. (2019) Коллективная память о событиях отечественной истории: социально-психологический подход. М. : Институт психологии РАН. 299 с. (Серия «Психология социальных явлений»).

Емельянова, Т. П., Кузнецова, А. В. (2013а) Значимые фигуры российской истории в коллективной памяти разных групп общества // Знание. Понимание. Умение. № 2. С. 123-129.

Емельянова, Т. П., Кузнецова, А. В. (2013b) Представления коллективной памяти об эпохе Петра I и его личности у представителей различных социальных групп // Психологические исследования. Т. 6. № 28. C. 9. URL: http: //psystudy.ru/index.php/num/2013v6n28/809-emelyanova28.html [архивировано в WaybackMachine] (дата обращения: 10.05.2020).

Кириллов, В. В., Бравина, М. А. (2016) История России : учебник. М. : Юрайт. 502 с.

Костомаров, Н. И. (1892) Русская история в жизнеописаниях ее главнейших деятелей : [в 4 т.]. 3-е изд. СПб. : Тип. М. М. Стасюлевича. Т. 2: Господство дома Романовых до вступления на престол Екатерины II : (Продолжение). XVIII-ое столетие. [4], 349, [2] с.

Костомаров, Н. И. (1995) Русская история в жизнеописаниях ее главнейших деятелей : в 2 кн. М. : СВАРОГ. Кн. 2: Выпуски пятый, шестой, седьмой. $816 \mathrm{c.}$

Ли Цзин. (2015) Поляризованность русской национальной личности: Образ Петра Первого // Русский язык в современном Китае : IV Международная научно-практическая конференция (г. Хайлар, КНР, Институт русского языка и культуры Хулуньбуирского института, 2-5 октября 2015 г.) : сб. науч.метод. ст. / под ред. Л. В. Вороновой. Чита : Забайкальский гос. ун-т. 167 с. С. 113-120.

Мезенцев, С. Д., Мезенцев, И. С. (2018) Петр I как выдающийся политический лидер // Вестник Забайкальского государственного университета. Т. 24. № 5. C. 87-94. DOI: 10.21209/2227-9245-2018-24-5-87-94

Палеолог, М. В., Чистова, С. М. (2014) Сакральный аспект имперской идеологии России. Имперская идеология в эпоху Петра I и XIX веке // Обозреватель - Observer. № 9 (296). С. 64-74. 
Саркисьян, И. И. (2014) Доктрина модернизации: Россия от Петра I до «сталинской революции» // Вестник Московского университета. Сер. 18: Coциология и политология. № 3. С. 169-178.

Сахаров, А. Н., Боханов, А. Н. (2013) История России. XVIII-XIX века. Ч. 2: учебник для 10 класса общеобразовательных учреждений / под общ. ред. чл.-корр. РАН А. Н. Сахарова. 11-е изд. М. : ООО «Русское слово - учебник». $288 \mathrm{c}$.

Дата поступления: 12.05.2020 2.

\section{REFERENCES}

Akunin, B. (2017) Aziatskaia evropeizatsiia. Istoriia Rossiiskogo gosudarstva. Tsar' Petr Alekseevich [Asian Europeanization. History of the Russian state. Tsar Peter Alekseevich]. Moscow : AST Publ. 384 p. (In Russ.).

Andreev, I. L. et al. (2019) Istoriia Rossii. Konets XVII - XVIII vek. 8 klass [History of Russia. The late 17th - 18th century. The 8th grade] : A textbook / I. L. Andreev, L. M. Liashenko, I. V. Amosova, I. A. Artasov and I. N. Fedorov. 5th edn., revised. Moscow : Drofa Publ. 218, [6] p (In Russ.).

Anisimov, E. V. (2017) Petr Pervyi: blago ili zlo dlia Rossii? [Peter the Great: Good or bad for Russia?]. Moscow : Novoe literaturnoe obozrenie Publ. 272 p. (In Russ.).

Artemov, V. V. and Lubchenkov, Yu. N. (2017) Istoriia Otechestva. S drevneishikh vremen do nashikh dnei [The history of Fatherland. From ancient times to the present day] : A textbook for students of secondary vocational education organizations. 21st edn., stereotype. Moscow : Akademiia Publ. 384 p. (In Russ.).

Bushkov, A. A. (2018) Peterburg i peterburzhtsy ili paradiz Petra I [Petersburg and Petersburgers or the paradise of Peter I]. Moscow : Kapital Publ. 320 p. (In Russ.).

Valizade, D. R. (2011) Reformy Petra I kak osnova transformatsii kul'turnykh tsennostei v Rossii [Reforms of Peter I as the basis for the transformation of cultural values in Russia]. Sovremennye nauchnye issledovaniia i innovatsii, no. 5. [online] Available at: http://web.snauka.ru/issues/2011/09/2611 [archived in WaybackMachine] (accessed 02.04.2020). (In Russ.).

Danilov, A. G. (2015) Rossiia na perekrestkakh istorii XIV-XIX vv. [Russia at the crossroads of the history in the 14th-19th centuries]. St. Petersburg : Aleteiia Publ. 436, [3] p. (In Russ.).

Dvornichenko, A. Yu., Kashchenko, S. G. and Florinskii, M. F. (2016) Istoriia Rossii do 1917 goda [History of Russia before 1917] : A textbook. Moscow : Urait Publ. 453 p. (In Russ.). 
Dzhabbarov, R. R. (2019) Petr Velikii v otsenke N. M. Karamzina [Peter the Great in N. M. Karamzin's reflections]. Vestnik Volgogradskogo gosudarstvennogo universiteta. Seriia 4: Istoriia. Regionovedenie. Mezhdunarodnye otnosheniia, vol. 24, no. 1, pp. 98-108. (In Russ.). DOI: 10.15688/jvolsu4.2019.1.8

Emelyanova, T. P. (2019) Kollektivnaia pamiat' o sobytiiakh otechestvennoi istorii: sotsial'no-psikhologicheskii podkhod [Collective memory of events in Russian history: A socio-psychological approach]. Moscow : Publ. House of the Institute of Psychology RAS. 299 p. (Series «Psikhologiia sotsial'nykh iavlenii» / "Psychology of social phenomena”). (In Russ.).

Emelyanova, T. P. and Kuznetsova, A. V. (2013a) Znachimye figury rossiiskoi istorii v kollektivnoi pamiati raznykh grupp obshchestva [The significant persons of Russian history in the collective memory of various social groups]. Znanie. Ponimanie. Umenie, no. 2, pp. 123-129. (In Russ.).

Emelyanova, T. P. and Kuznetsova, A. V. (2013b) Predstavleniia kollektivnoi pamiati ob epokhe Petra I i ego lichnosti u predstavitelei razlichnykh sotsial'nykh grupp [Representations of collective memory concerning epoch and personality of Peter the Great in representatives of various social groups]. Psikhologicheskie issledovaniia, vol. 6, no. 28, pp. 9. [online] Available at: http://psy study.ru/index.php/num/2013v6n28/809-emelyanova28.html [archived in WaybackMachine] (accessed 10.05.2020). (In Russ.).

Kirillov, V. V. and Bravina, M. A. (2016) Istoriia Rossii [History of Russia] : A textbook. Moscow : Urait Publ. 502 p. (In Russ.).

Kostomarov, N. I. (1892) Russkaia istoriia $v$ zhizneopisaniiakh ee glavneishikh deiatelei [Russian history in the biographies of its main figures] : [in 4 vols.]. 3rd edn. St. Petersburg : M. M. Stasiulevich’ Printing House. Vol. 2: Gospodstvo doma Romanovykh do vstupleniia na prestol Ekateriny II : (Prodolzhenie). XVIII-oe stoletie [The domination of the House of Romanov before the accession of Catherine II to the throne. The 18th century]. [4], 349, [2] p. (In Russ.).

Kostomarov, N. I. (1995) Russkaia istoriia $v$ zhizneopisaniiakh ee glavneishikh deiatelei [Russian history in the biographies of its main figures] : in 2 books. Moscow : SVAROG Publ. Bk. 2: Vypuski piatyi, shestoi, sed'moi [The fifth, sixth, and seventh issues]. 816 p. (In Russ.).

Li Jing. (2015) Poliarizovannost' russkoi natsional'noi lichnosti: Obraz Petra Pervogo [Polarization of the Russian national personality: The image of Peter the Great]. In: Russkii iazyk v sovremennom Kitae [The Russian language in contemporary China] : The 4th International science-to-practice conference (Hailar, CPR, Institute of the Russian Language and Culture, Hulunbuir Institute, October 2-5, 2015) : A collection of articles / ed. by L. V. Voronova. Chita : Transbaikal State University Publ. 167 p. Pp. 113-120. (In Russ.). 
Mezentsev, S. D. and Mezentsev, I. S. (2018) Petr I kak vydaiushchiisia politicheskii lider [Peter I as an outstanding political leader]. Vestnik Zabaikal'skogo gosudarstvennogo universiteta, vol. 24, no. 5, pp. 87-94. (In Russ.). DOI: $10.21209 / 2227-9245-2018-24-5-87-94$

Paleolog, M. V. and Chistova, S. M. (2014) Sakral'nyi aspekt imperskoi ideologii Rossii. Imperskaia ideologiia v epokhu Petra I i XIX veke [Sacral aspect of the imperial ideology of Russia. Imperial ideology in the era of Peter I and the 19th century]. Obozrevatel' - Observer, no. 9 (296), pp. 64-74. (In Russ.).

Sarkisian, I. I. (2014) Doktrina modernizatsii: Rossiia ot Petra I do «stalinskoi revoliutsii» [The doctrine of modernization: Russia from Peter I to the "Stalinist revolution”]. Vestnik Moskovskogo universiteta. Seriia 18: Sotsiologiia i politologiia, no. 3, pp. 169-178. (In Russ.).

Sakharov, A. N. and Bokhanov, A. N. (2013) Istoriia Rossii. XVIII-XIX veka [History of Russia. 18th-19th centuries]. Pt. 2: A textbook for the 10th grade of general education institutions / ed. by A. N. Sakharov. 11th edn. Moscow : Russkoe slovo - uchebnik Publ. 288 p. (In Russ.).

Submission date: 12.05.2020.

Емельянова Татьяна Петровна - доктор психологических наук, профессор, ведущий научный сотрудник лаборатории социальной и экономической психологии Института психологии РАН. Адрес: 129366, Россия, г. Москва, ул. Ярославская, д. 13, к. 1. Тел.: +7 (962) 969-18-31. Эл. адрес: t_emelyanova@inbox.ru

Emelyanova Tatiana Petrovna, Doctor of Psychology, Professor, Leading Researcher, Laboratory of Social and Economic Psychology, Institute of Psychology, Russian Academy of Sciences. Postal address: Bldg. 1, 13 Yaroslavskaya St., 129366 Moscow, Russian Federation. Tel.: +7 (962) 969-18-31. E-mail: t emelyanova@inbox.ru

ScopusID: 6508104219

ReseacherID: K-3655-2017

SPIN-код РИНЦ: $\underline{4338-1645}$

Для циитирования:

Емельянова Т. П. Трактовки личности Петра Первого в современной науке и коллективной памяти россиян [Электронный ресурс] // Горизонты гуманитарного знания. 2020. № 3. C. 59-70. URL: https://journals.mosgu.ru/ ggz/article/view/1212 (дата обращения: дд.мм.гггг). DOI: 10.17805/ggz.2020.3.5 